\title{
Metabolic diversity and co-occurrence of multiple Ferrovum species at an acid mine drainage site
}

\author{
Christen L. Grettenberger ${ }^{1}$, Jeff R. Havig ${ }^{2}$ and Trinity L. Hamilton $34^{*}$
}

\begin{abstract}
Background: Ferrovum spp. are abundant in acid mine drainage sites globally where they play an important role in biogeochemical cycling. All known taxa in this genus are Fe(II) oxidizers. Thus, co-occurring members of the genus could be competitors within the same environment. However, we found multiple, co-occurring Ferrovum spp. in Cabin Branch, an acid mine drainage site in the Daniel Boone National Forest, KY.

Results: Here we describe the distribution of Ferrovum spp. within the Cabin Branch communities and metagenome assembled genomes (MAGs) of two new Ferrovum spp. In contrast to previous studies, we recovered multiple 165 rRNA gene sequence variants suggesting the commonly used $97 \%$ cutoff may not be appropriate to differentiate Ferrovum spp. We also retrieved two nearly-complete Ferrovum spp. genomes from metagenomic data. The genomes of these taxa differ in several key ways relating to nutrient cycling, motility, and chemotaxis.

Conclusions: Previously reported Ferrovum genomes are also diverse with respect to these categories suggesting that the genus Ferrovum contains substantial metabolic diversity. This diversity likely explains how the members of this genus successfully co-occur in Cabin Branch and why Ferrovum spp. are abundant across geochemical gradients.
\end{abstract}

Keywords: Ferrovum, Carbon fixation, Iron oxidation, Metagenome, Acidophlic, Biofilm, Microcosm, Co-occurrence, Nitrogen, Denoised sequence variants

\section{Background}

Iron-oxidizing bacteria are common in mine-impacted water and acid mine drainage (AMD) environments which are typically characterized by low $\mathrm{pH}$ and high concentrations of dissolved metals [1-3]. Betaproteobacteria of the genus Ferrovum play important roles in biogeochemical cycling in AMD environments including carbon fixation and rapid oxidation of iron [4-9] and could be of value in bioremediation [10]. However, Ferrovum spp. are challenging and labor-intensive to culture and isolate because

\footnotetext{
* Correspondence: trinityh@umn.edu

${ }^{3}$ Department of Plant and Microbial Biology, University of Minnesota, 218 Cargill Building, St. Paul, MN 55108, USA

${ }^{4}$ The BioTechnology Institute, University of Minnesota, St. Paul, MN 55108, USA

Full list of author information is available at the end of the article
}

they often co-occur with heterotrophic Acidiphilium spp. or other Fe(II) oxidizers [7, 11, 12]. Indeed, Ferrovum myxofaciens strain P3 is the only Ferrovum spp. in culture to date, highlighting the value and need for characterization of this enigmatic genus via molecular techniques.

Ferrovum spp. occur in AMD environments with diverse geochemistry. Ferrovum spp. are abundant at sites with $\mathrm{pH}$ ranging from less than 3 to $7[4-6,13,14]$ and with iron concentrations ranging from $2 \mu \mathrm{M}$ [5] to $71 \mathrm{mM}$ [7]. High-throughput sequencing and 'omics techniques have aided in characterizing the metabolic potential of Ferrovum via non-culture-based techniques [15-18] across these large gradients of $\mathrm{Fe}$ and $\mathrm{pH}$. These studies indicate that Ferrovum is a diverse genus composed of six clades (Groups I - VI) of closely related species and strains [18]. Still, only four Ferrvoum genomes are publicly

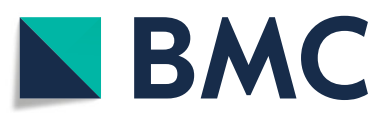

(c) The Author(s). 2020 Open Access This article is licensed under a Creative Commons Attribution 4.0 International License, which permits use, sharing, adaptation, distribution and reproduction in any medium or format, as long as you give appropriate credit to the original author(s) and the source, provide a link to the Creative Commons licence, and indicate if changes were made. The images or other third party material in this article are included in the article's Creative Commons licence, unless indicated otherwise in a credit line to the material. If material is not included in the article's Creative Commons licence and your intended use is not permitted by statutory regulation or exceeds the permitted use, you will need to obtain permission directly from the copyright holder. To view a copy of this licence, visit http://creativecommons.org/licenses/by/4.0/. The Creative Commons Public Domain Dedication waiver (http://creativecommons.org/publicdomain/zero/1.0/) applies to the data made available in this article, unless otherwise stated in a credit line to the data. 
available and these are from Ferrovum Groups I and IV. No genomes have been reported for Groups, II, III, or V. The published genomes and culture studies suggest that Ferrovum spp. are autotrophs that pair Fe(II) oxidation with carbon fixation $[7,15,16,18,19]$. Ferrovum spp. play important roles in nutrient cycling and some members of the genus also fix nitrogen [7, 19]. However, sequenced Ferrovum genomes have variable genomes especially with genes associated with motility, chemotaxis, biofilm formation, and nitrogen metabolism [15]. Furthermore, Ferrovum dominated communities exhibit morphological differences, including forming large streamers $[5,7,14]$ or low extracellular polymeric substances [4] though it can be difficult to identify EPS in low pH environments [16]. These differences may help explain how Ferrovum is able to occupy a large range of $\mathrm{pH}$ and ferrous iron concentrations in AMD environments. However, the potential genetic and metabolic diversity within the genus is underrepresented because there are no cultured representatives or genomes available for several Ferrovum clades.

In our previous studies of Cabin Branch, we reported the predominance of a single operational taxonomic unit (OTU; 97\% similarity) in our 16S rRNA amplicon data most closely related to F. myxofaciens at this AMD site in the Daniel Boone National Forest in southern Kentucky. This taxon was abundant in diverse morphotypes including filament, floc, and 'brain' or 'spongy' mat biofilms over a pH range of 2.1 to 2.4 and $\mathrm{Fe}(\mathrm{II})$ concentrations of 448 to $5200 \mu \mathrm{mol} / \mathrm{L}$ [5]. Based on these data, we employed a cultivation-independent approach to characterize the genetic diversity and functional potential of this taxon using $16 \mathrm{~S}$ rRNA amplicons and by examining the gene content of metagenome assembled genomes (MAGs) from the site.

\section{Results}

\section{Geochemistry}

All aqueous geochemistry data are reported in Table 1 . $\mathrm{pH}$ values were acidic, ranging from 2.90 to 2.97 from the source to Rose Pool (Fig. 1). Temperatures were highest at the source $\left(14.6^{\circ} \mathrm{C}\right)$ and decreased down the outflow channel to $8.1^{\circ} \mathrm{C}$ at the Rose Pool, consistent with warm groundwater cooling after emerging due to relatively cool ambient temperatures $\left(\sim 0{ }^{\circ} \mathrm{C}\right.$ at the time of sampling). Conductivity increased from $940 \mu \mathrm{S} / \mathrm{cm}$ at the emergence to $2063 \mu \mathrm{S} / \mathrm{cm}$ at Rose Pool. Dissolved oxygen increased from a low of $77.5 \mu \mathrm{mol} / \mathrm{L}$ at the emergence sampling site to a high of $401 \mu \mathrm{mol} / \mathrm{L}$ (close to saturation) at Rose Pool. Anion concentrations in Cabin Branch were dominated by sulfate (9.51 to $10.08 \mathrm{mmol} / \mathrm{L})$, with lower concentration of chloride (166 to $220 \mu \mathrm{mol} / \mathrm{L}$ ). Cation concentrations were highest at the emergence and nearby first outflow sites, and lowest at the Rose Pool, including calcium ( 1.20 to $0.39 \mathrm{mmol} / \mathrm{L}$ ), magnesium (0.69 to 0.20
Table 1 Geochemical and physical features for Cabin Branch samples

\begin{tabular}{|c|c|c|c|c|c|c|c|}
\hline \multicolumn{2}{|l|}{ Location: } & \multicolumn{2}{|c|}{ Emergence } & \multicolumn{2}{|l|}{ LLC } & \multicolumn{2}{|c|}{ Rose Pool } \\
\hline Parameter & (Units) & Value & S.D. & Value & S.D. & Value & $\overline{\text { S.D. }}$ \\
\hline$\overline{\mathrm{pH}}$ & & 2.90 & & 2.92 & & 2.97 & \\
\hline $\mathrm{mV}$ & & 235 & & 232 & & 224 & \\
\hline Temperature & $\left({ }^{\circ} \mathrm{C}\right)$ & 14.6 & & 13.7 & & 8.1 & \\
\hline Conductivity & $(\mu \mathrm{S} / \mathrm{cm})$ & 940 & & 1853 & & 2063 & \\
\hline D.O. & $(\mu \mathrm{mol} / \mathrm{L})$ & 77.5 & & 266 & & 401 & \\
\hline $\mathrm{Fe} 2+$ & $(\mu \mathrm{mol} / \mathrm{L})$ & 403.2 & & 882.0 & & 11.16 & \\
\hline $\mathrm{NH} 4(\mathrm{~T})$ & $(\mu \mathrm{mol} / \mathrm{L})$ & 35.7 & & 50.0 & & 10.7 & \\
\hline DIC & $(\mathrm{mmol} / \mathrm{L})$ & 1.67 & & 0.48 & & 0.30 & \\
\hline 813CVPDB & $(\% 0)$ & -15.96 & 0.08 & -13.03 & 0.08 & -11.79 & 0.08 \\
\hline DOC & $(\mu \mathrm{mol} / \mathrm{L})$ & 40.51 & 0.90 & 44.19 & 3.27 & 36.82 & 6.42 \\
\hline 813CVPDB & $(\% 0)$ & -22.50 & 1.53 & -23.09 & 0.84 & -23.95 & 0.29 \\
\hline $\mathrm{Cl}$ & $(\mu \mathrm{mol} / \mathrm{L})$ & 175.58 & 1.10 & 220.04 & 61.99 & 166.13 & 0.44 \\
\hline $\mathrm{SO} 4$ & $(\mathrm{mmol} / \mathrm{L})$ & 9.96 & 0.16 & 9.51 & 0.14 & 10.08 & 0.06 \\
\hline 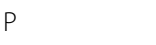 & $(\mu \mathrm{mol} / \mathrm{L})$ & 9.55 & 0.49 & 4.49 & 0.35 & bdl & \\
\hline $\mathrm{Na}$ & $(\mathrm{mmol} / \mathrm{L})$ & 0.12 & 0.00 & 0.12 & 0.03 & 0.03 & 0.00 \\
\hline K & $(\mathrm{mmol} / \mathrm{L})$ & 0.17 & 0.00 & 0.18 & 0.04 & 0.03 & 0.00 \\
\hline $\mathrm{Ca}$ & $(\mathrm{mmol} / \mathrm{L})$ & 1.121 & 0.028 & 1.198 & 0.256 & 0.390 & 0.007 \\
\hline $\mathrm{Mg}$ & $(\mathrm{mmol} / \mathrm{L})$ & 0.666 & 0.012 & 0.686 & 0.156 & 0.201 & 0.001 \\
\hline $\mathrm{Al}$ & $(\mu \mathrm{mol} / \mathrm{L})$ & 1755 & 125 & 1201 & 0.26 & 187.4 & 1.2 \\
\hline $\mathrm{Si}$ & $(\mu \mathrm{mol} / \mathrm{L})$ & 1528 & 35 & 1454 & 66 & nd & \\
\hline $\mathrm{Mn}$ & $(\mu \mathrm{mol} / \mathrm{L})$ & 76.84 & 0.63 & 43.19 & 0.13 & 40.23 & 0.28 \\
\hline FeTotal & $(\mu \mathrm{mol} / \mathrm{L})$ & 4684 & 22 & 4154 & 50 & 249.6 & 1.8 \\
\hline
\end{tabular}

Geochemical and physical measurements: meters/probes $(\mathrm{pH}$,

$\mathrm{mV}$, Temperature,

Conductivity, Dissolved Oxygen (D.O.)), spectrophotometry (Fe(II), $\mathrm{NH} 4(\mathrm{~T})$ ), ion chromatography (Cl, SO4), IR-MS (dissolved inorganic carbon (DIC), dissolved organic carbon (DOC), ICP-OES (P, Na, K, Ca, Mg, Si, italisized values for Al and FeTotal), and ICP-MS (Al, Mn, Fe). LLC = limestonelined channel, S.D. = standard deviation, bdl = below detection limits,

$\mathrm{mmol} / \mathrm{L})$, potassium $(0.18$ to $0.03 \mathrm{mmol} / \mathrm{L})$, and sodium (0.12 to $0.03 \mathrm{mmol} / \mathrm{L})$.

Dissolved inorganic carbon (DIC, predominantly present as dissolved $\mathrm{CO}_{2}$ due to the low $\mathrm{pH}$ ) concentration was highest at the emergence $(1.67 \mathrm{mmol} / \mathrm{L})$ and decreased down the outflow channel to $0.30 \mathrm{mmol} / \mathrm{L}$ at the Rose Pool. DIC $\delta^{13} \mathrm{C}$ values were more negative at the source $\left(\delta^{13} \mathrm{C}=-15.96 \%\right)$ and became more positive down the outflow channel with the most positive values at the Rose Pool $\left(\delta^{13} \mathrm{C}=-11.79 \%\right)$, consistent with preferential loss of ${ }^{12} \mathrm{CO}_{2}$ through volatilization and uptake by autotrophs. Dissolved organic carbon concentration was consistently low at all sites (36.8 to $44.2 \mu \mathrm{mol} /$ L) and had similar $\delta^{13} \mathrm{C}$ values $(-22.50$ to $-23.95 \%$ ).

Potential nutrients measured included $\mathrm{NH}_{4}(\mathrm{~T}), \mathrm{P}, \mathrm{Mn}$, $\mathrm{Fe}(\mathrm{II})$, and $\mathrm{Fe}_{\text {(total) }}$. $\mathrm{NH}_{4}(\mathrm{~T})$ concentration was highest at the first outflow site $(50.0 \mu \mathrm{mol} / \mathrm{L})$ and lowest at Rose Pool $(10.7 \mu \mathrm{mol} / \mathrm{L})$. P concentration was highest at the 
emergence $(9.55 \mu \mathrm{mol} / \mathrm{L})$ and decreased to below detection limits at the Rose Pool. Mn concentration decreased from the highest value at the emergence $(76.84 \mu \mathrm{mol} / \mathrm{L})$ to the lowest at the Rose Pool $(40.23 \mu \mathrm{mol} / \mathrm{L})$. Total iron $\left(\mathrm{Fe}_{\text {total }}\right)$ exhibited a similar trend as $\mathrm{Mn}$ and $\mathrm{P}$, with the highest concentration at the emergence $(4684 \mu \mathrm{mol} / \mathrm{L})$ and the lowest at the Rose Pool in the outflow $(249.6 \mu \mathrm{mol} / \mathrm{L})$, though $\mathrm{Fe}(\mathrm{II})$ had concentrations significantly lower than $\mathrm{Fe}_{\text {total }}$ with the highest concentration at the outflow site downstream of the emergence $(882 \mu \mathrm{mol} / \mathrm{L})$ and the lowest at the Rose Pool $(11.2 \mu \mathrm{mol} / \mathrm{L})$.

\section{Inorganic carbon assimilation}

Autotrophic incorporation of added ${ }^{13} \mathrm{CO}_{2}$ was quantified in mesocosm experiments using treatments carried out under either light or dark (wrapped in aluminum foil) to characterize photoautotrophic and chemoautotrophic uptake, respectively. At the emergence, both green and white biomass was observed and autotrophic incorporation of ${ }^{13} \mathrm{CO}_{2}$ was quantified in both biofilm types. Because we assumed the majority of uptake in the green biomass would be due to photoautotrophy and we could not control for oxygen production in this treatment, we performed one set of microcosms on the bulk biofilm in the light and then separated the biofilm types (green or white) for microcosms performed in the dark. In the light treatments of full biofilms (green and white biomass) C-uptake rates averaged $32.547( \pm 7.949)$ and 21.691 ( \pm 6.36) $\mu \mathrm{g} \mathrm{C}$ uptake/g $\mathrm{C}_{\text {biomass }} / \mathrm{hr}$. after one- and two-hour incubations, respectively. Dark treatments of the green biomass returned averages of $1.632( \pm 0.454)$ $\mu \mathrm{g} \mathrm{C}$ uptake/g $\mathrm{C}_{\text {biomass }} / \mathrm{hr}$. after 1 hour and $0.746( \pm$ 0.174) $\mu \mathrm{g} C$ uptake/g $C_{\text {biomass }} /$ hr. after 2 hours, while dark treatments of the white biomass returned averages of $0.305( \pm 0.403) \mu \mathrm{g} \mathrm{C}$ uptake/g $C_{\text {biomass }} /$ hr. after 1 hour and $0.662( \pm 0.240) \mu \mathrm{g} \mathrm{C}$ uptake/g $\mathrm{C}_{\text {biomass }} / \mathrm{hr}$. after 2 hours. Biofilms with both green and white biomass together from the limestone-lined channel immediately downstream of the emergence returned average Cuptake rates of $35.947( \pm 5.516)$ and $15.085( \pm 0.106) \mu \mathrm{g}$ $\mathrm{C}$ uptake/g $\mathrm{C}_{\text {biomass }} / \mathrm{hr}$. for light treatments of one and two hours respectively and $2.586( \pm 0.148)$ and $1.245( \pm$ 0.035) $\mu \mathrm{g} C$ uptake/g $C_{\text {biomass }} / \mathrm{hr}$. for dark treatments after one and two hours. Rose Pool sediment incubations returned average C-uptake rates of $1.372( \pm 0.061) \mu \mathrm{g} \mathrm{C}$ uptake/g $\mathrm{C}_{\text {biomass }} / \mathrm{hr}$. for light treatments of 2 hours and 0.066 ( \pm 0.132$) \mu \mathrm{g} \mathrm{C}$ uptake/g $\mathrm{C}_{\text {biomass }} / \mathrm{hr}$. for dark treatments of 2 hours. All C-uptake results are reported in Supplementary Table S1.

\section{$16 S$ rRNA}

Thirty two thousand one hundred twenty four qualitycontrolled sequences were retrieved from the emergence, 41,988 from the limestone-lined channel, and 37,546 from the Rose Pool. These sequences were affiliated with 82,276 , and 286 denoised sequence variants (DSVs) respectively. Cabin Branch contains nine DSVs closely related to Ferrovum myxofaciens (Fig. 2). Four DSVs are present in the emergence sample, five in the limestone lined channel, and eight in Rose Pool (Figs. 1 and 2). DSVs affiliated with Ferrovum are most abundant in the limestone lined channel where they compose $32.8 \%$ of the community and least abundant in the Rose Pool where they compose $5.0 \%$ of the community. Ferrovum DSVs compose $29.6 \%$ of the emergence community. The abundance of each DSV varies between samples. DSVs $4,10,12$, and 81 are the most abundant Ferrovum DSVs in the Emergence community, 4, 10, 12, 34, and 59 in the limestone lined channel, and DSVs 56 and 81 in the Rose Pool (Fig. 3). The DSVs are phylogenetically placed within Ferrovum groups I, II, III and between Groups IV and V (Fig. 2).

\section{Metagenomics}

$74,021,852$ to $101,886,314$ metagenomic reads were retrieved per sample with an average GC content of $55 \%$ (Supplementary Table S2). Fourteen bins were retrieved that were phylogenetically placed within the genus Ferrovum. The resulting MAGs ranged from low- to highquality drafts based on quality and contamination, but lack 16S rRNA gene sequences [20]. Five of these bins were retrieved from individually assembled metagenomes and 9 from the combined assembly. Based on average nucleotide identity (ANI), each of the Ferrovum bins from the individual assemblies was also present in the combined assembly and one bin was represented in the emergence, terrace, and combined assemblies (Supplementary Table S3). For MAGs that were present in more than one assembly, the highest quality bin from that MAG was used for further analysis (Table 2). Nine unique Ferrovum MAGs were present in the dataset. These MAGs shared 68.5 to $88.5 \%$ ANI with each other and between 68.6 and 99.4\% ANI with published Ferrovum genomes (Supplementary Table S3). Based on a concatenated tree of ribosomal protein genes, eight of the nine MAGs occupy the phylogenetic space between the Group I Ferrovum sp. JA12 and sp. PN-J185 and the Group IV Ferrovum sp. Z-31 and the type strain (Fig. 4). Two MAGs, MAG-4 and MAG-7 are > 85\% complete and have limited contamination. Therefore, we have described them in more detail below.

\section{MAG-4}

MAG-4 is represented by a single bin which was retrieved from the combined assembly and is the most complete MAG recovered in this study. It is $95.7 \%$ complete with $0.4 \%$ contamination. MAG-4 contains 


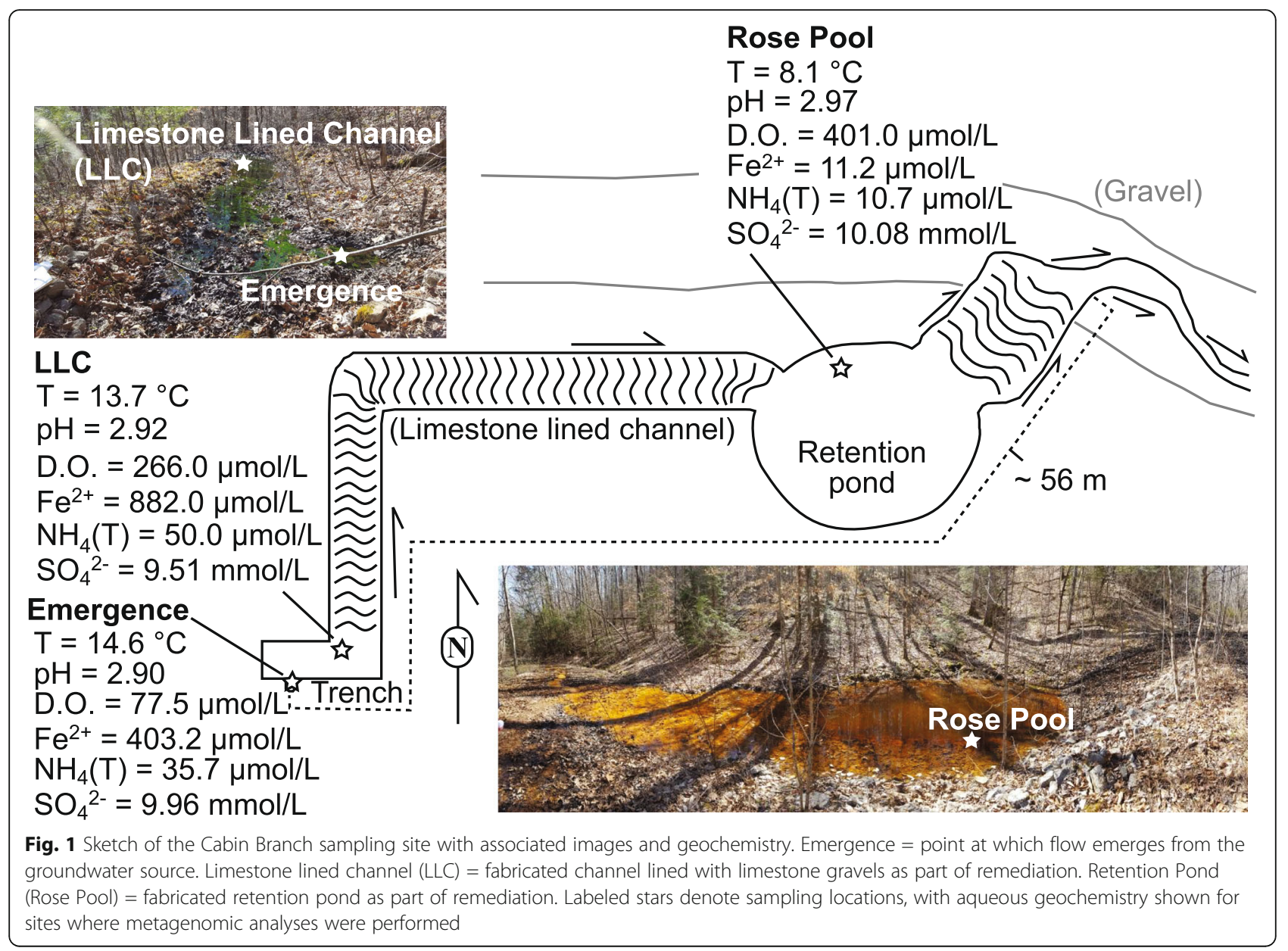

2250 gene coding sequences, 1466 of which were annotated by GhostKoala (Table 2). MAG-4 shares 69-74\% ANI with the other MAGs and the published Ferrovum genomes (Supplementary Table S3). The MAG is phylogenetically positioned between the Group I Ferrovum spp. JA12 and PN-J185 and the Group VI type strain and sp. Z-31 (Fig. 4)

\section{Energy metabolism}

MAG-4 contains three homologs of the high molecular weight, Cyc-2-like protein previously found in Ferrovum spp. (Figs. 5 and 6). This protein is thought to facilitate the oxidation of $\mathrm{Fe}(\mathrm{II})$ to $\mathrm{Fe}(\mathrm{III})$ [16]. The MAG also contains homologs of the genes necessary for oxidative phosphorylation using a B/A type NADH dehyrodgenase $(n u o A-n u o N)$ and succinate dehydrogenase $(s d h A-D)$, a $\mathrm{E} / \mathrm{B} / \mathrm{A}$ type cytochrome $c$ reductase, $c b b_{3}$ and $b d$ type terminal oxidases, and an F-type ATPase (Fig. 6).

\section{Carbohydrate metabolism}

MAG-4 encodes the enzymes necessary to fix carbon via the Calvin-Benson cycle except the enzyme needed to form ribose 5-phosphate from sedoheptulose-7 phosphate. The MAG also contains the genes for a nearly complete TCA cycle. It contains a nearly complete suite of genes for glycolysis.

\section{Nutrient acquisition}

MAG-4 encodes the structural proteins necessary for nitrogen fixation (NifHDK) and denitrification (NasAB, NirBD), but lacks the genes necessary to import inorganic nitrogen into the cell (Fig. 6). The MAG contains many of the genes necessary for assimilatory sulfate reduction but is missing PAPSS which reduces ammonium persulfate (APS) to 3-phosphoadenosine-5-phosphosulfate (PAPS). It also contains homologs of DsrA and DsrB which can be used to reduce sulfite to sulfide or to oxidize sulfide to sulfite (Fig. 6). The MAG also contains the genes necessary to import inorganic phosphate and use it in biosynthetic pathways (PST, $p p x, p p k$ ).

\section{Motility}

MAG-4 contains all the genes necessary to construct flagella except $\operatorname{mot} X Y$ which encode proteins are involved in flagellar rotation and fliJT. The MAG also contains the genes necessary for chemotaxis (cheABCD, cheR, and cheVWZ) 


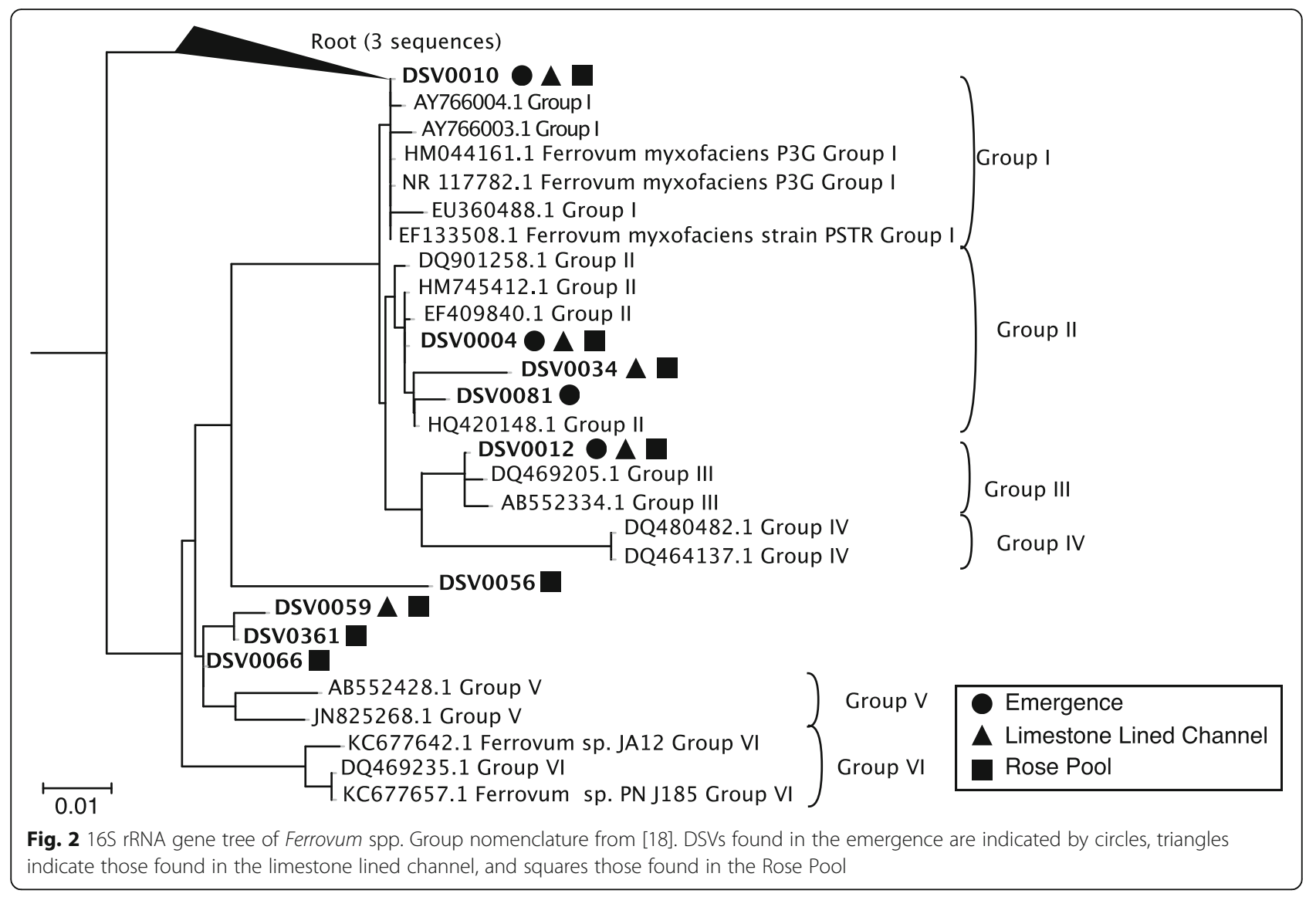

Table 2 Metagenome assembled genomes. When a taxon was found in multiple assemblies, the MAG with the highest completeness and lowest contamination was used. The MAGs used for further analysis are shown in black text whereas those not used are shown in grey text. The MAGs used in the comparative analysis are highlighted by in grey

\begin{tabular}{|c|c|c|c|c|c|c|}
\hline Name & Bin ID & Completeness & Contamination & Heterogeneity & $\begin{array}{l}\text { Protein Coding } \\
\text { Sequences }\end{array}$ & $\begin{array}{l}\text { Annotated } \\
\text { Sequences }\end{array}$ \\
\hline MAG 1 & Combined_89 & 20.69 & 0 & 0 & & \\
\hline MAG 2 & Combined_19 & 44.72 & 0.42 & 66.67 & & \\
\hline \multirow[t]{2}{*}{ MAG 3} & Rose Pool 43 & 68.75 & 4.13 & 18.18 & & \\
\hline & Combined_70 & 58.28 & 5.17 & 40 & & \\
\hline MAG 4 & Combined_34 & 95.76 & 0.5 & 0 & 2250 & 1466 \\
\hline \multirow[t]{2}{*}{ MAG 5} & Combined_31 & 43.89 & 0 & 0 & & \\
\hline & Rose Pool 56 & 36.51 & 0 & 0 & & \\
\hline MAG 6 & Combined_120 & 42.16 & 1.72 & & & \\
\hline \multirow[t]{3}{*}{ MAG 7} & Limestone Lined Terr. 25 & 86.7 & 0.63 & 100 & 1764 & 1158 \\
\hline & Emergence 33 & 72.59 & 0 & 0 & & \\
\hline & Combined_101 & 70.86 & 0 & 0 & & \\
\hline \multirow[t]{2}{*}{ MAG 8} & Combined_72 & 86.37 & 33.74 & 80.26 & & \\
\hline & Emergence 23 & 83.17 & 54.31 & 81.58 & & \\
\hline MAG 9 & Combined_5 & 30.17 & 0 & 0 & & \\
\hline
\end{tabular}




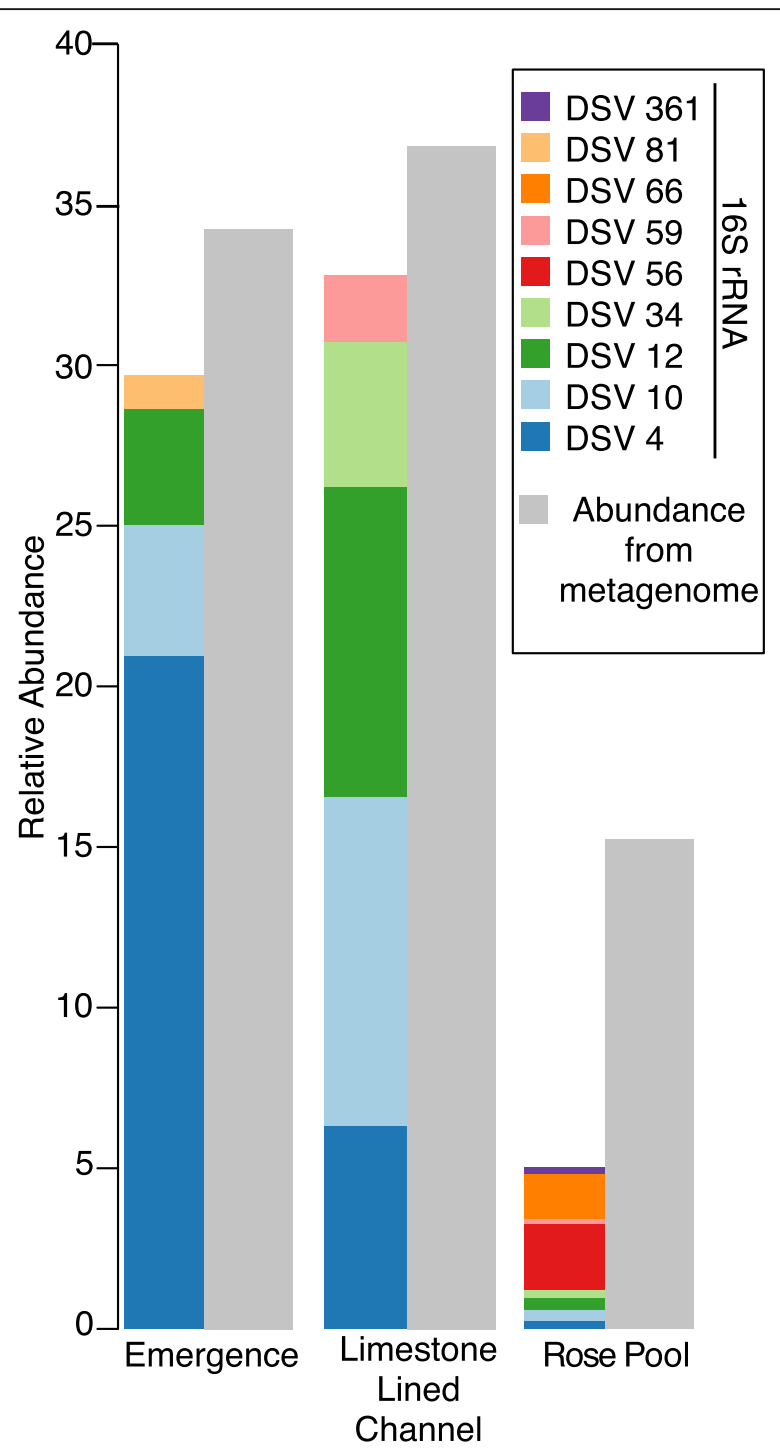

Fig. 3 Relative abundance of Ferrovum DSVs in each of the sampled communities as determined by $16 \mathrm{~S}$ rRNA sequencing. Each Ferrovum DSV is represented by a unique color. Grey bars indicate estimated abundance of Ferrovum from the metagenomic datasets

\section{MAG-7}

MAG-7 is represented by bins retrieved from the emergence, limestone lined channel, and co-assembled metagenomes (Table 2). The highest quality bin is from the limestone lined terrace and is $86.7 \%$ complete with $0.63 \%$ contamination. The other two bins are 72.6 and $70.9 \%$ complete with $0 \%$ contamination. Because the most complete bin is only $86.7 \%$ complete, when genes were absent from that bin, we searched the other two less complete bins

\section{Energy metabolism}

MAG-7 contains one homolog to the high-molecular weight Cyc2 type protein found in other Ferrovum taxa
(Figs. 5 and 6). The Cyc2 sequence is phylogenetically placed as a sister group to those from the type strain and Ferrovum sp. Z31 (Fig. 4). MAG-7 also contains homologs of the genes necessary for oxidative phosphorylation with a B/A type NADH dehydrogenase (nuoA$n u o N)$ and succinate dehydrogenase (sdhA-D), an E/B/A type cytochrome $c$ reductase, $b o, b d$, and $c b b_{3}$ type terminal oxidases, and an F-type ATP-ase.

\section{Nutrient acquisition}

MAG-7 encodes the genes necessary for reducing nitrate to nitrite (nas $A B)$, but not those to further reduce the nitrate to ammonia (nirBD; Fig. 6). The MAG also contains the genes necessary to import inorganic phosphate and use it in biosynthetic pathways (PST, ppx, ppk). MAG-7 does not encode protein necessary for nitrogen fixation and lacks the genes necessary to transform urea to ammonia.

\section{Carbohydrate metabolism}

MAG-7 contains most of the genes necessary for carbon fixation via the Calvin-Benson cycle but like MAG-4 does not encode the enzyme needed to form ribose 5phosphate from sedoheptulose-7 phosphate. The MAG encodes the proteins necessary for a complete TCA cycle. It contains a nearly complete suite of genes for glycolysis.

\section{Motility}

MAG-7 contains all the genes necessary to synthesize a functional flagellum except $\operatorname{mot} X$ and $\operatorname{mot} Y$ which are also missing from MAG-4. The MAG also contains genes involved in bacterial chemotaxis including $m c p$, aer, tar, cheABCD, cheR, and cheVY, but it does not appear to contain cheW and cheZ which are present in MAG-4.

\section{Discussion}

Co-occurrence of Ferrovum spp. in cabin branch communities

All known Ferrovum spp. are obligate, Fe (II) oxidizing autotrophs that use $\mathrm{O}_{2}$ as a terminal electron acceptor $[7,16,17]$. Therefore, co-occurring Ferrovum spp. would presumably compete for common resources if they exploited identical resources, possibly including Fe (II) and oxygen, essential nutrients (e.g., $\mathrm{N}$ and $\mathrm{P}$ ), and trace elements. At Cabin Branch, Fe (II) is present in $\mathrm{mmol} / \mathrm{L}$ amounts constantly supplied by mine-impacted sources and is unlikely to be limiting. Dissolved oxygen is also present although the concentration is lower at the emergence and increases downstream. Ammonia and phosphate were detected at all sites. Alternately, gene content differences could explain co-existence of Ferrovum populations at Cabin Branch. Co-occurring strains 


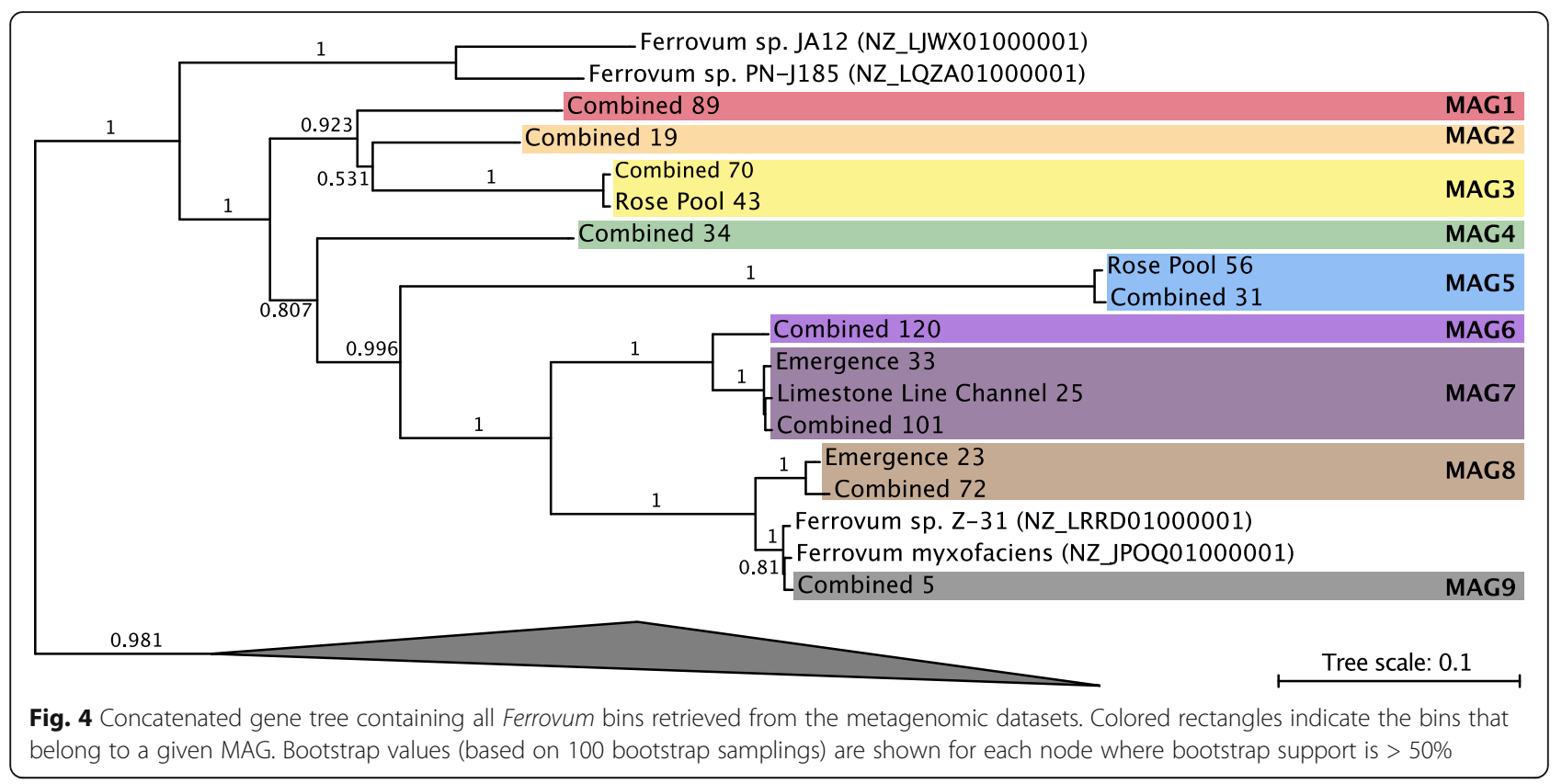

of the same species have been found in a variety of environments including cyanobacterial blooms [21], and solar saltern/crystallization ponds [22, 23]. In some communities, successful co-occurrence results from genomic variation or differential gene expression between the strains of the co-occurring species. For example, six cooccurring strains of the Epsilonproteobacteria Lebetimonas acquired new functional genes via lateral gene transfer in sea mounts in the Mariana Arc [24]. Similarly, strains of Salinabacter ruber contain hypervariable regions in their genome which are associated with differences in surface properties [22]. Co-occurring strains of $S$. ruber also express different metabolite pools [23]. These differences likely allow co-occurring strains to avoid competing within the environment [22, 24]. Like these communities, the Ferrovum spp. at Cabin Branch may be able to co-exist due to variations in their genomes or in gene expression $[7,16,17]$.

Ferrovum spp. compose over $25 \%$ of the bacterial community in the emergence and limestone lined channel communities and 5\% of the Rose Pool community, based on the 16S rRNA amplicon libraries. The relative abundance of Ferrovum spp. appears to increase with the rate of non-photosynthetic inorganic carbon assimilation (Fig. 7). These data suggest that these populations are important primary producers in the environment because Ferrovum spp. are the only abundant chemoautotroph and therefore, likely the main contributor to dark carbon fixation. Our previous work on samples collected in 2015 reported a single Ferrovum OTU in Cabin Branch. However, that analysis relied on a definition of $97 \%$ identity in 16S rRNA sequences [5] which is the

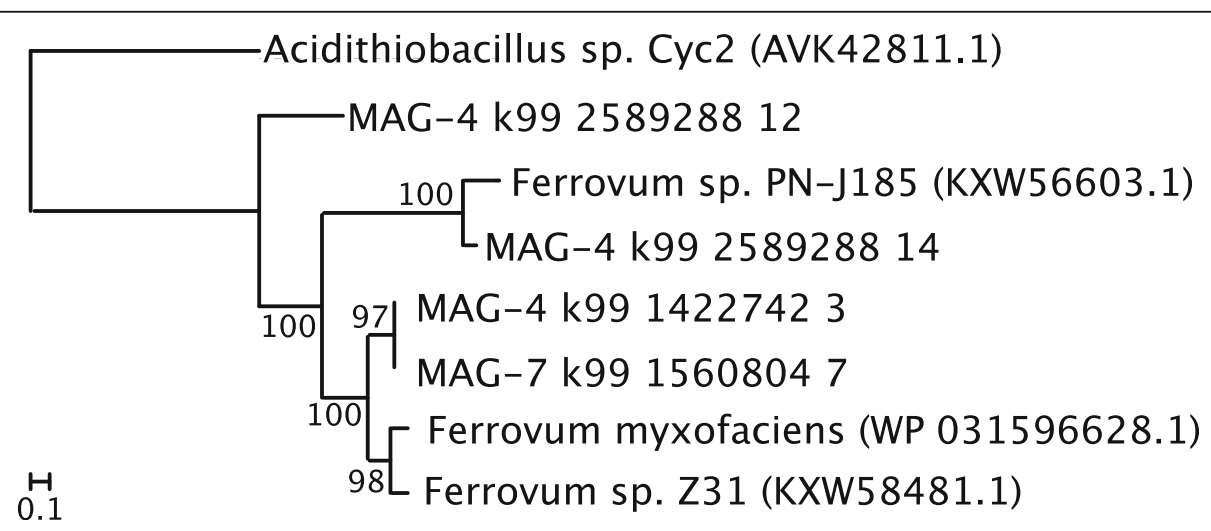

Fig. 5 Maximum likelihood phylogeny phylogeny of Cyc-2 like gene found in published Ferrovum genomes and the MAGs retrieved in this study. Accession numbers are provided in parentheses. Numbers represent bootstrap support values based on 100 bootstrap samplings 


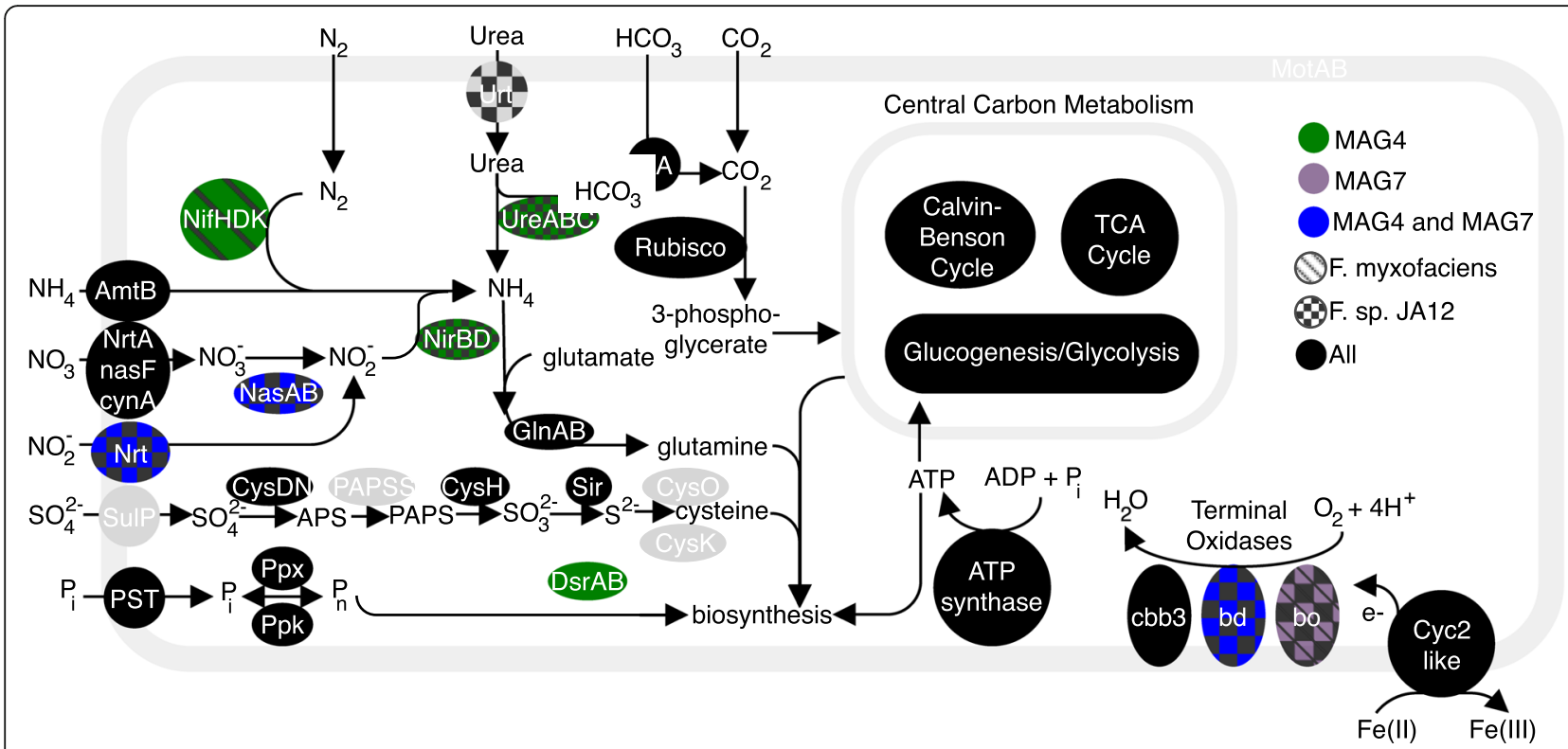

Fig. 6 Potential cycling of C, S, P, and N in Ferrovum MAGs from Cabin Branch as predicted by the gene content of the MAGs. Proteins are color coded based on their presence or absence in each genome. Modeled after [18]

common cutoff for delineating species based on $16 \mathrm{~S}$ rRNA gene sequence identity level, but likely underestimates bacterial diversity [25]. Currently, methods using unique sequences are becoming more common and may be more robust [26, 27]. Using a DSV approach on samples collected in 2017 as part of this research, we recovered nine unique Ferrovum taxa: four Ferrovum DSVs co-occur in the emergence community, five in the limestone lined channel, and eight in the Rose Pool sediments (Figs. 2 and 3). Genome-based studies using average nucleotide identity (ANI) and multilocus phylogenetic analysis are more robust than 16S rRNA-based analyses and are the best practice for assigning species affiliations in genomes [28]. Metagenomic data from Cabin Branch support the presence of multiple Ferrovum spp. at each site, suggesting that the diversity of Ferrovum spp. at AMD sites globally may be underestimated because studies have traditionally used an OTU approach $[4,5]$.

To co-occur successfully, the strains may partition the niche to use different resources as is seen in closelyrelated taxa or intraspecific competitors in eukaryotic systems [29-31]. If phylogenetic distance correlates with metabolic diversity, we might expect co-occurring strains of Ferrovum would be distantly related. Indeed, those that co-occur in the Cabin Branch communities span the Group I, II, and III Ferrovum clades and the limestone lined channel and Rose Pool also include DSVs that are not placed within a clade (Fig. 1). However, some co-occurring Ferrovum spp. are closely related to one another. Multiple DSVs from the same
Ferrovum group are found in the same microbial community. For example, two Group II DSVs are found in all three communities sampled and the Rose Pool community contains three closely related DSVs phylogenetically placed basally to the Group V Ferrovum (Fig. 2). Therefore, phylogenetic distance may not determine whether taxa can coexist. However, published Ferrovum taxa vary in their gene content with respect to genes associated with motility and nitrogen cycling among others, likely due to lateral gene transfer $[15,16,18]$. Therefore, we can examine how genome content may allow co-occurring taxa to partition resources and avoid competition.

\section{Relating two new Ferrovum spp. (MAG-4 and MAG-7) to published species}

Here, we compared our Ferrovum MAGs to two published Ferrovum species from Ferrovum Groups I (F. myxofaciens sp. P3G) and IV (Ferrovum sp. JA12) to explore if genomic variability could contribute to the cooccurrence of these taxa. Our two Ferrovum MAGs and the Group I and Group IV genomes share numerous features, but differ in key ways relating to energy metabolism, nitrogen cycling, and motility. Because the MAGs are incomplete, we only consider a feature to be missing if all of genes that code for key enzymes related to that feature are absent from the MAG.

\section{Energy metabolism}

All cultured Ferrovum spp. can grow autotrophically via iron oxidation $[7,15,16,18,19]$ and we predict that the 


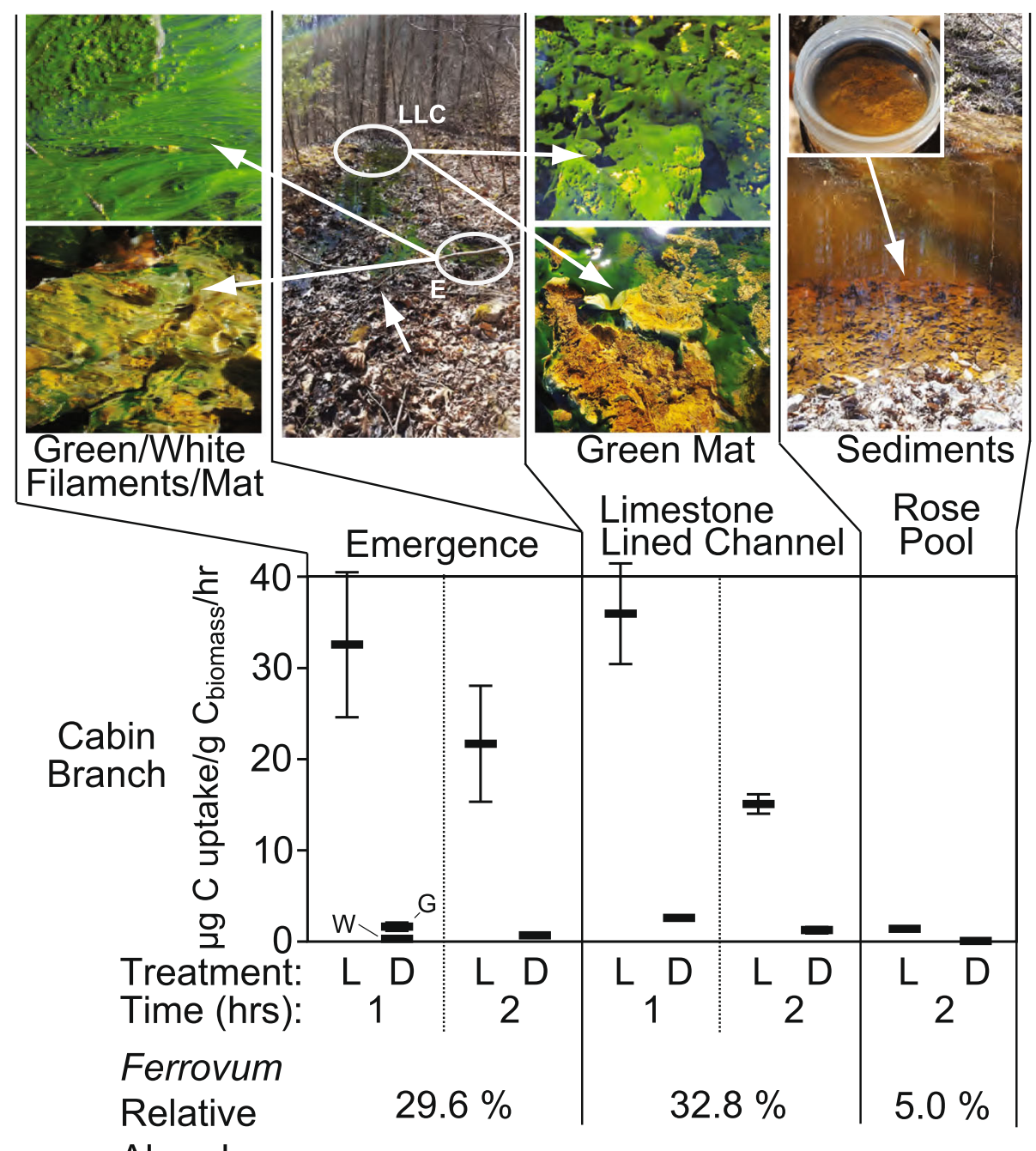

Fig. 7 Images and carbon uptake rates for Cabin Branch emergence (E), limestone lined channel (LLC), and Rose Pool retention pond sites. $L=$ light treatment, $\mathrm{D}=$ dark treatment (wrapped in aluminum foil), $\mathrm{W}=$ white filaments $/$ mat, $\mathrm{G}=$ green filaments/mat

two MAGs presented here share that ability. Each genome contains high molecular weight, Cyc2-like proteins found in other Ferrovum taxa [16]. In the acidophilic Fe oxidizers Acidithiobacillus ferrooxidans and a Leptospirillum spp. Cyc2 is an Fe oxidase [32, 33]. Cyc2-like proteins are also highly expressed in neutrophilic $\mathrm{Fe}(\mathrm{II})$ oxidizers [33-35]. Therefore, this protein likely plays a role in Fe(II) oxidation in Ferrovum. In Acidithiobacillus ferrooxidans and Gallionella ferruginea, $\mathrm{Fe}(\mathrm{II})$ oxidation is paired with carbon fixation. The MAGs encode a nearly full suite of genes for carbon fixation via the CBB pathway but differ in the types of terminal oxidases they use for oxidative phosphorylation (Fig. 5). MAG-7, F. myxofaciens sp. P3G, and Ferrovum sp. JA12 all contain cytochrome $b_{3}$ type oxidases, but MAG-4 does not contain this type of cytochrome. Similarly, MAGs 4 and 7 and Ferrovum sp. JA12 contain a cytochrome bd-type quinol oxidase which is not present in $F$. myxofaciens sp. P3G (Fig. 5). Terminal oxidases differ in their affinity for oxygen and are differentially expressed depending on the concentration of oxygen [34]. For example, E. coli express cytochrome $b_{3}$ under oxic conditions, and cytochrome $b d$, which has a higher affinity for $\mathrm{O}_{2}$, under oxygen limiting conditions [34]. MAG-4 lacks genes for cytochrome $b o_{3}$ which may indicate that this taxon does not colonize well-oxygenated environments that may be more suitable for MAG-7, F. myxofaciens sp. P3G, and Ferrovum sp. JA12. Similarly, MAGs 4 and 7 and Ferrovum sp. JA12 may be able to colonize microaerobic environments that are not ideal for F. myxofaciens sp. P3G which lacks high affinity terminal oxidases. In Cabin Branch, these differences may lead to MAGs 4 and 7 
preferentially inhabiting different portions of the biofilm with MAG-7 inhabiting the better oxygenated surface of the biofilms and MAG-4 residing in more microaerobic niches within the biofilm.

\section{Nitrogen cycling}

Ferrovum myxofaciens sp. P3G can fix nitrogen, but this trait is not conserved within the genus. Neither Ferrovum sp. Z-31 nor PN-J185 are capable of nitrogen fixation [15, 18]. At Cabin Branch, MAG-4 encodes the enzymes necessary for $\mathrm{N}$-fixation $(\mathrm{NifH}, \mathrm{D}$, and K) and the hydrolysis of urea (Fig. 6) while MAG7 does not. The ability to fix nitrogen would allow MAG-4 to colonize low $\mathrm{NH}_{4}$ environments. Additionally, it may influence where MAG-4 resides in the biofilm community as nitrogenase proteins are oxygen sensitive [36]. Therefore, MAG-4 may preferentially reside in low-oxygen environments that provide enough oxygen to perform $\mathrm{Fe}(\mathrm{II})$ oxidation, but at low enough concentrations to protect nitrogenase from oxidative damage. This idea is supported by the presence of $c b b_{3}$ and $b d$ type oxidases in MAG-4 that are preferentially expressed in microaerobic conditions as discussed above.

\section{Motility}

Ferrovum spp. vary in their ability to be motile. Ferrovum sp. JA-12 and the closely related Ferrovum sp. PNJ185 lack genes both for flagella and for chemotaxis whereas F. myxofaciens sp. P3G contains the genes necessary for a functional flagellum $[9,15-17,19]$. The MAGs from Cabin Branch are more similar to F. myxofaciens sp. P3G in this respect, because they encode the genes necessary for the synthesis of a functional flagellum. MAG-7 and F. myxofaciens sp. P3G also contain homologs of tar, a chemotaxis related protein that responds to the presence of aspartate or maltose and aer which produces a protein that allow a chemotactic response to redox state $[37,38]$ potentially indicating that these taxa can respond to different environmental cues than MAG-4 which lacks these genes.

\section{Conclusions}

We recovered co-occurring Ferrovum taxa with distinct metabolisms from the emergence and outflow of an AMD site. A DSV-based approach suggested multiple Ferrovum taxa co-occur which contrasts to previous OTU-based studies [5]. These data and the Ferrovum genomes recovered from metagenomic data highlight the limits of using OTU clustering approaches in identifying discrete species. We also identified the metabolic diversity among closely related Ferrovum spp. that likely facilities the co-occurrence of these taxa. Specifically, the differences in nutrient cycling, motility, and chemotaxis may facilitate co-occurrence without direct competition for resources. These physiological differences may also help to explain why Ferrovum spp. are nearly ubiquitous in AMD environments despite the geochemical diversity of these environments. These data help fill in gaps of missing diversity in the Ferrovum clade which are ubiquitous in AMD environments but difficult to culture. Finally, our data highlight genetic diversity necessary for closely related co-occurring species.

\section{Methods}

\section{Site location and sampling}

Cabin Branch is a site in the Daniel Boone National Forest in Kentucky near the border with Tennessee. Limestone was added to the channel as a passive remediation strategy and groundwater flows out from an emergence and across a limestone-lined channel before entering a pond, the Rose Pool (Figs. 1 and 7). The microbial communities within Cabin Branch are predominantly the Fe (II)-oxidizing taxon Ferrovum myxofaciens [5] Samples were collected on March 16, 2017 between 10 am and 2 pm. Sample collection was approved by and performed in collaboration with the staff at Daniel Boone National Forest.

\section{Geochemical analyses \\ Aqueous geochemistry}

At the time of sample collection, temperature and $\mathrm{pH}$ were measured and recorded using a WTW 330i meter and probe (Xylem Analytics, Weilheim, Germany). A YSI 30 conductivity meter and probe (YSI Inc., Yellow Springs, OH, USA) was used to measure conductivity. Total ammonia $\left(\mathrm{NH}_{4}(\mathrm{~T})=\mathrm{NH}_{3}+\mathrm{NH}_{4}{ }^{+}\right)$and ferrous iron (Fe(II)) concentration were determined using Hach DR1900 Portable Spectrometers (Hach Company, Loveland, $\mathrm{CO}$ ) using the salicylate method (Hach Method 8155) and the phenanthroline method (Hach Method 8146), respectively.

To examine water geochemistry including major ions, major cations, trace elements, and carbon concentration and isotopes, samples were collected and stored following previously described methods [39-41]. In brief, samples were collected in a $140-\mathrm{mL}$ syringe, filtered through $0.8 / 0.2 \mu \mathrm{m}$ polyethersulfone syringe filters, and dispensed into $15-\mathrm{mL}$ polypropylene centrifuge tubes (for major anions), acid-washed $15-\mathrm{mL}$ polypropylene centrifuge tubes (for major cations and trace elements), Labco Exetainers ${ }^{\bullet}$ (Labco Limited, Lampeter, UK) preflushed with $\mathrm{He}$ (for dissolved inorganic carbon (DIC)), and sterile $50-\mathrm{mL}$ centrifuge tubes (for dissolved organic carbon (DOC)). Major anions were determined at the Analytical Geochemistry Laboratory in the Department of Earth and Environmental Sciences at the University of Minnesota using a Thermo Scientific Dionex ICS 5000+ 
ion chromatography system. Were stored in $15 \mathrm{~mL}$ polypropylene centrifuge tubes. Major cations and trace metals were determined at the Analytical Geochemistry Laboratory in the Department of Earth and Environmental Sciences using a Thermo Scientific iCAP 6000 series ICP-OES (inductively coupled plasma optical emission spectroscopy) or a Thermo Scientific X Series 2 ICP-MS (inductively coupled plasma mass spectrometry). DIC concentration and ${ }^{13} \mathrm{C}$ isotopic signal analyses were performed on a GasBench II system interfaced to a Delta V Plus isotope ratio mass spectrometer (IR-MS) (Thermo Scientific, Bremen, Germany) by the Stable Isotope Facility (SIF) at the University of California, Davis for analysis. DOC concentration and ${ }^{13} \mathrm{C}$ isotopic signal analyses were performed on a O.I. Analytical Model 1030 TOC Analyzer (O.I. Analytical, College Station, TX, USA) by the SIF at UC-Davis. The standard deviation for DOC was determined from replicate analyses of each sample. For each analysis, field blanks were taken using $18.2 \mathrm{M} \Omega / \mathrm{cm}$ deionized water transported to the field in 1-1 acid washed Nalgene bottles for comparison to samples.

Colorimetric tests are optimized for $20^{\circ} \mathrm{C}$ and are known to have chemical interferences, thus the spectrophotometrically derived Fe(II) concentrations should be considered semi-quantitative whereas $\mathrm{Fe}_{\text {total }}$ is measured via ICP-MS or ICP-OES with samples that are acidified with concentrated $\mathrm{HNO}_{3}$ to keep metals in solution. Our assumption is that the majority of $\mathrm{Fe}_{\text {total }}$ is $\mathrm{Fe}(\mathrm{II})$ and most $\mathrm{Fe}(\mathrm{III})$ present precipitates immediately as $\mathrm{Fe}$ $(\mathrm{OH})_{3(\mathrm{~S})}$ and is collected on $0.2 \mu \mathrm{m}$ filters during sample collection.

\section{$\mathrm{CO}_{2}$ assimilation}

In situ microcosms were performed to assess the potential for inorganic carbon uptake through the addition of $\mathrm{NaH}^{13} \mathrm{CO}_{3}$. Sample collection and the microcosm set-up followed previously described methods [39-41]. In summary, samples (biofilms, filaments, etc.) were place in sterile serum vials, overlaid with spring water, capped, and amended with $\mathrm{NaH}^{13} \mathrm{CO}_{3}(100 \mu \mathrm{M}$ final concentration) (Cambridge Isotope Laboratories, Inc., Andover, MA, USA). All assays were performed in triplicate between $10 \mathrm{AM}$ and $2 \mathrm{PM}$. To assess the potential for photoautotrophic $\mathrm{NaH}^{13} \mathrm{CO}_{3}$ uptake, microcosms were incubated in the light. In contrast, microcosms were wrapped in foil to assess the potential for chemoautotrophic (dark) $\mathrm{NaH}^{13} \mathrm{CO}_{3}$ uptake. At the emergence, both green and white filaments were present. We performed assays on each by sampling predominantly green filaments and predominantly white filaments. We assumed the majority of uptake in the green biomass would be due to photoautotrophy and thus performed one set of microcosms on the bulk filaments/biofilm (green + white) in the light and then separated the biofilm types (green or white) for microcosms performed in the dark. Following incubation, vials were flash frozen on dry ice and stored at $-80^{\circ} \mathrm{C}$ until processed (described below). Calculation of assimilation rates is described below.

\section{$C$ and $N$ concentration and stable isotope signals}

Samples for ${ }^{13} \mathrm{C}$ natural abundance were collected at the time of sampling using sterile spatulas. These were flash frozen on dry ice, stored in liquid $\mathrm{N}_{2}$ for transport and stored at $-80{ }^{\circ} \mathrm{C}$ until processed. To examine ${ }^{13} \mathrm{C}$ signals in natural abundance samples and microcosms, samples were acidified (for microcosms), dried, and weighed following previously described methods [39-41]. Samples were analyzed via an Elementar pyrocube elemental analyzer (EA) periphery connected to an Isoprime 100 continuous flow IRMS (IR-MS) at the University of Minnesota. NIST Standard 2710 was used for linearity corrections. $\delta^{13} \mathrm{C}$ values were calibrated using reference standards USGS-40 and USGS-41 and checked with a laboratory working standard (glycine). The following precautions were taken to minimize cross contamination of natural abundance samples with samples that were amended with $\mathrm{NaH}^{13} \mathrm{CO}_{3}$ : natural abundance samples were processed, weighed, and analyzed separate from labeled samples and all laboratory processing and weighing equipment was cleaned with $80 \%$ ethanol between each sample. In addition, to check for memory effects or cross contamination of samples, standard checks and blanks were included with each analysis batch (no memory effects or cross contamination were detected). Assimilation rates were calculated as described previously [39-41] using difference between the total amount of ${ }^{13} \mathrm{C}$ in natural abundance samples and incubation assay replicates which represents total mass of ${ }^{13} \mathrm{C}$-labelled DIC in biomass after the incubation period ( $1-2 \mathrm{~h})$. We performed a one-way ANOVA followed by post hoc pairwise comparisons within the $\mathrm{R}$ software package ( $\mathrm{R}$ version 3.3.2) to compare mean ${ }^{13} \mathrm{C}$ uptake rates and considered $p$-values $<0.05$ as significantly different.

\section{Molecular analyses \\ DNA extraction}

Triplicate samples for DNA extraction were collected at the time of sampling using sterile spatulas, flash frozen onsite and stored at $-80^{\circ} \mathrm{C}$ until processed. DNA was extracted from each replicate sample $(n=3)$ using a DNeasy PowerSoil Kit (Qiagen, Carlsbad, CA, USA) according to the manufacturer's instructions and quantified using a Qubit 3.0 Fluorometer (Invitrogen, Burlington, ON, Canada). Equal volumes of each extraction were pooled and submitted to the University of Minnesota Genomics Center (UMGC) for amplicon 
sequencing. As a negative DNA extraction control, we attempted to extract DNA from the filters used for the field blank water samples (described above). These extractions failed to yield detectable DNA and failed library preparation for amplicon sequencing (see below for amplicon sequencing details).

\section{DNA sequencing}

Amplicons were sequenced at the UMGC with MiSeq Illumina $2 \times 300$ bp chemistry targeting the V4 hypervariable region of bacterial and archaeal 16S SSU rRNA gene sequences (515F and 806r) [42] as described previously [40].

Preparation of amplicon libraries followed the UMGC's improved protocol to detect which taxonomic groups that often go undetected using existing methods [43]. Each sample was sequenced once. Total DNA was submitted to the UMGC for metagenomic sequencing and sequenced using HiSeq2500 High-Output $2 \times 125$ bp chemistry. Three samples were sequenced / lane.

\section{S rRNA analysis}

16S rRNA sequences from Cabin Branch were used to examine community composition. Primers and unpaired sequences were removed using trimmomatic [44]]) The surviving reads were processed in dada2 (v.1.4) following the pipeline tutorial [27]. Briefly, forward reads were trimmed to $210 \mathrm{bp}$ and reverse reads were trimmed to $120 \mathrm{bp}$ based on their quality profiles. Sequences with ambiguous bases and those with more than 2 expected errors were removed. Error rates were estimated using the learnErrors command. Sequences were dereplicated using the derepFastq command and the unique sequence variates were inferred using the dada command. Forward and reverse reads were merged using mergePairs. Contigs shorter than 250 or longer than $256 \mathrm{bp}$ and chimeric sequences were removed. The surviving unique, denoised sequences are referred to as denoised sequence variants (DSVs). Taxonomy was assigned using the Silva training set [45] Eukaryotic sequences and those unclassified at the domain level were removed. The closest cultured and environmental relatives were identified using BLASTN [46].

We retrieved 1589 aligned, nearly-full length Ferrovum sequences from the Silva non-redundant database to serve as a reference alignment for the analyses described below. A $16 \mathrm{~S}$ rRNA phylogeny was constructed by retrieving the sequences used by Ullrich et al. [18] with Ferritrophicum radicicola, Nitrospovibrio tenuis, and Nitrospira lenta used as an outgroup. These sequences were aligned using MAFFT on the Cipres Science Gateway [47] using the aligned Ferrovum sequences from the Silva database as a reference alignment. A tree of the smaller subset of sequences was constructed in RAXML-
HPC2 on XSEDE [48] also on the Cipres Science Gateway. Sequences of DSVs classified as Ferrovum were added to the alignment using the -addfrags option in MAFFT [49]. Non-full-length sequences were added to the tree using the evolutionary placement algorithm. Trees were rooted and visualized in the interactive tree of life [50]. Raw sequences were uploaded to the NCBI Sequence Read Archive under BioProject PRJNA554371.

\section{Metagenomic analysis}

Individual metagenomes were assembled and a co-assembly of all metagenomes was constructed following the "tutorial on assembly-based metagenomics" [51]].Trimmed, qualitycontrolled sequences were assembled using MegaHit [52] using default parameters except minimum contig length, which was set at 1000 base pairs. Reads were mapped to the assembly using bowtie2 [53] and depth was calculated using the jgi_summarize_bam_contig_depths command in Anvi'o [54]. Contigs were binned using default parameters in metabat using [55]. Bin completeness was determined with CheckM [56]. Protein coding regions were identified with prodigal (within CheckM) [57] and GhostKoala was used to annotate protein coding sequences [58]. Pathways were considered to be absent from the taxon when none of the key genes associated with that pathway were present in the MAG.

Each bin was uploaded to KBASE [59] and annotated with Prokka using the "Annotate Assembly and Reannotate Genomes with Prokka (v1.12)" app. A concatenated gene tree containing each bin and four published Ferrovum spp. genomes was constructed using the "Insert Set of Genomes Into Species Tree 2.1.10" app. This app uses up to 49 ribosomal and single-copy genes to construct a phylogenetic tree. MAGs that were more closely related to Ferrovum spp. than other taxa were selected for further analysis. The pairwise ANI between each bin and published Ferrovum genomes was calculated using anvicompute-ani in Anvi'o. If MAGs shared > 98\% pairwise ANI and were phylogenetically cohesive, we considered them to be representing the same populations and the bin with the highest completeness was chosen for further analysis. Raw reads, assemblies, and MAGs were uploaded to the NCBI Sequence Read Archive under BioProject PRJNA554371. The abundance of Ferrovum in each metagenomes using One Codex [60].

16S rRNA A custom blast database containing the $16 \mathrm{~S}$ rRNA gene from the Ferrovum myxofaciens type strain (NR_117782.1) using the makeblastdb command in BLAST+. Each of the Ferrovum bins were searched for 16S rRNA genes using BLAST and a cutoff value of E-30. 
Cyc-2 A custom blast database of the high molecular weight Cyc-2 like proteins was constructed using the methods described above. Each of the Ferrovum bins were searched for the Cyc-2-like protein identified by Ullrich et al., [16] by blasting translated nucleotide sequences against the blast database with an E-value of E-120. The retrieved sequences, database sequences, and a sequence for Cyc-2 from an Acidithiobacillus sp. (AVK42811.1) were aligned using MAFFT and a maximum likelihood tree was constructed as described above. The tree was rooted on Acidithiobacillus and visualized in iTOL.

\section{Comparison with other Ferrovum genomes}

Existing Ferrovum genomes are located within either the Group I or Group IV Ferrovum clades [18]. The genome for Ferrovum sp. JA12 (Group I) and Ferrovum myxofaciens (Group IV) were downloaded from NCBI. CheckM was used to determine genome completeness, and within CheckM, prodigal was used to identify protein coding sequences. Ghost KOALA was used to annotate protein coding sequences using the genus_prokaryotes database. Protein coding sequences were also annotated with prokka. We then manually compared the gene content of MAGs to that of existing Ferrovum genomes.

\section{Supplementary information}

Supplementary information accompanies this paper at https://doi.org/10. 1186/s12866-020-01768-w.

Additional file 1: Table S1. Carbon uptake experiment results.

Additional file 2: Table S2. Sequencing and assembly statistics for metagenomes used in this research.

Additional file 3: Table S3. Average nucleotide identity of MAGs retrieved from the Cabin Branch metagenomes.

\section{Abbreviations}

AMD: Acid mine drainage; ANI: Average nucleotide identity; APS: Ammonium persulfate 3-phosphoadenosine-5-phosphosulfate; DIC: Dissolved inorganic carbon; DSV: Denoised sequence variants; ICP-MS: Inductively coupled plasma mass spectrometry; ICP-OES: Inductively coupled plasma atomic emission spectroscopy; MAG: Metagenome assembled genomes; PAPS: 3phosphoadenosine-5-phosphosulfate; TCA: Tricarboxylic acid cycle

\section{Acknowledgements}

We are grateful to the staff of the National Forest Service and Daniel Boone National Forest, especially Margueritte Wilson and Claudia Cotton, for the advice and insight regarding mine locations. We thank A. Gangidine, M. Berberich, R. Jain, and C. Schuler for assistance in field sampling and processing samples in the laboratory.

\section{Authors' contributions}

$\mathrm{JRH}, \mathrm{CLG}$, and TLH contributed to the conception of the project, data analysis interpretation of results, creation of figures, writing and editing the manuscript. JRH and TLH performed sample collection and sample analysis. The authors have read and approve of the manuscript.

\section{Funding}

This work was supported by the University of Cincinnati and the University of Minnesota. The authors acknowledge the Minnesota Supercomputing Institute (MSI) at the University of Minnesota for providing resources that contributed to the research results reported within this paper. The funders had no role in the design of the study and collection, analysis, and interpretation of data.

\section{Availability of data and materials}

All analyses tools used in the study are publicly available. 16S rRNA and functional genes of closely related species and outgroups were downloaded from NCBI databases and accession numbers are provided for these sequences. Raw reads and assembled scaffolds for the metagenomes and MAG sequences as well as the amplicon libraries have been deposited in the NCBI under BioProject PRJNA554371.

Ethics approval and consent to participate

Not applicable.

\section{Consent for publication}

Not applicable.

\section{Competing interests}

The authors declare that they have no competing interests.

\section{Author details}

${ }^{1}$ Department of Earth and Planetary Sciences, University of California, Davis, CA 95616, USA. ${ }^{2}$ Department of Earth and Environmental Sciences, University of Minnesota, Minneapolis, MN 55455, USA. ${ }^{3}$ Department of Plant and Microbial Biology, University of Minnesota, 218 Cargill Building, St. Paul, MN 55108, USA. ${ }^{4}$ The BioTechnology Institute, University of Minnesota, St. Paul, MN 55108, USA.

Received: 23 July 2019 Accepted: 29 March 2020

Published online: 18 May 2020

\section{References}

1. Baker BJ, Banfield JF. Microbial communities in acid mine drainage. FEMS Microbiol Ecol. 2003;44:139-52.

2. Johnson DB. Chemical and microbiological characteristics of mineral spoils and drainage waters at abandoned coal and metal mines. Water Air Soil Pollut Focus. 2003:3:47-66.

3. Schippers A, Breuker A, Blazejak A, Bosecker K, Kock D, Wright TL. The biogeochemistry and microbiology of sulfidic mine waste and bioleaching dumps and heaps, and novel Fe (II)-oxidizing bacteria. Hydrometallurgy. 2010;104:342-50.

4. Grettenberger $C L$, Pearce AR, Bibby KJ, Jones DS, Burgos WD, Macalady JL. Efficient low-pH iron removal by a microbial iron oxide mound ecosystem at scalp level run. Appl Environ Microbiol. 2017;83:e00015-7.

5. Havig JR, Grettenberger C, Hamilton TL. Geochemistry and microbial community composition across a range of acid mine drainage impact and implications for the Neoarchean-Paleoproterozoic transition. J Geophys Res Biogeosciences. 2017;122:1404-22.

6. Jones DS, Kohl C, Grettenberger C, Larson LN, Burgos WD, Macalady JL. Geochemical niches of iron-oxidizing acidophiles in acidic coal mine drainage. Appl Environ Microbiol. 2015;81:1242-50.

7. Johnson DB, Hallberg KB, Hedrich S. Uncovering a microbial enigma: isolation and characterization of the streamer-generating, iron-oxidizing, acidophilic bacterium "Ferrovum myxofaciens". Appl Environ Microbiol. 2014; 80:672-80.

8. Hallberg KB, Coupland K, Kimura S, Johnson DB. Macroscopic streamer growths in acidic, metal-rich mine waters in North Wales consist of novel and remarkably simple bacterial communities. Appl Environ Microbiol. 2006; 72:2022-30.

9. Schlömann M, Kipry J, Mosler S, Poehlein A, Keller A, Janneck E, et al. Physiological, genomic, and proteomic characterization of new "Ferrovum" strains obtained from a pilot plant for mine-water treatment. Adv Mat Res. 2013:825:149-52.

10. Johnson DB. Acidophilic microbial communities: candidates for bioremediation of acidic mine effluents. Int Biodeter Biodegr. 1995;35:41-58.

11. Kipry J, Jwair RJ, Gelhaar N, Wiacek C, Janneck E, Schlömann M. Enrichment of "Ferrovum" spp. and Gallionella relatives using artificial mine water. Adv Mat Res. 2013;825:54-7.

12. Tischler JS, Jwair RJ, Gelhaar N, Drechsel A, Skirl A-M, Wiacek C, et al. New cultivation medium for "Ferrovum" and Gallionella-related strains. J Microbiol Methods. 2013;95:138-44. 
13. Kuang J-L, Huang L-N, Chen L-X, Hua Z-S, Li S-J, Hu M, et al. Contemporary environmental variation determines microbial diversity patterns in acid mine drainage. ISME J. 2013;7:1038.

14. Kay C, Rowe O, Rocchetti L, Coupland K, Hallberg K, Johnson D. Evolution of microbial "streamer" growths in an acidic, metal-contaminated stream draining an abandoned underground copper mine. Life. 2013;3:189-210.

15. Ullrich SR, González C, Poehlein A, Tischler JS, Daniel R, Schlömann M, et al. gene loss and horizontal gene transfer contributed to the genome evolution of the extreme acidophile "Ferrovum". Front Microbiol. 2016;7:797.

16. Ullrich SR, Poehlein A, Tischler JS, González C, Ossandon FJ, Daniel R, et al. Genome analysis of the biotechnologically relevant acidophilic iron oxidising strain JA12 indicates phylogenetic and metabolic diversity within the novel genus "Ferrovum". PLoS One. 2016;11:e0146832.

17. Mosler S, Poehlein A, Voget S, Daniel R, Kipry J, Schlömann M, et al. Predicting the metabolic potential of the novel iron oxidising bacterium "Ferrovum" sp. JA12 using comparative genomics. Adv Mat Res. 2013;825:153-6.

18. Ullrich SR, Poehlein A, Daniel R, Tischler JS, Vogel S, Schlömann M, et al. Comparative genomics underlines the functional and taxonomic diversity of novel "Ferrovum" related iron oxidizing bacteria. Adv Mat Res. 2015;1130:15-8.

19. Moya-Beltrán A, Cárdenas JP, Covarrubias PC, Issotta F, Ossandon FJ, Grail $\mathrm{BM}$, et al. Draft genome sequence of the nominated type strain of "Ferrovum myxofaciens," an acidophilic, iron-oxidizing betaproteobacterium. Genome Announc. 2014;2:e00834-14.

20. Bowers RM, Kyrpides NC, Stepanauskas R, Harmon-Smith M, Doud D, Reddy TBK, et al. Minimum information about a single amplified genome (MISAG) and a metagenome-assembled genome (MIMAG) of bacteria and archaea. Nat Biotechnol. 2017;35:725.

21. Willis A, Woodhouse JN, Ongley SE, Jex AR, Burford MA, Neilan BA. Genome variation in nine co-occurring toxic Cylindrospermopsis raciborskii strains. Harmful algae. 2018;73. J Bacteriol. 2008;190:157-66.

22. Peña A, Teeling H, Huerta-Cepas J, Santos F, Yarza P, Brito-Echeverría J, et al. Fine-scale evolution: genomic, phenotypic and ecological differentiation in two coexisting Salinibacter ruber strains. ISME J. 2010;4:882.

23. Antón J, Lucio M, Peña A, Cifuentes A, Brito-Echeverría J, Moritz F, et al. High metabolomic microdiversity within co-occurring isolates of the extremely halophilic bacterium Salinibacter ruber. PLoS One. 2013;8:e64701.

24. Meyer $J$, Huber JA. Strain-level genomic variation in natural populations of Lebetimonas from an erupting deep-sea volcano. ISME J. 2014;8:867.

25. Rodriguez-R LM, Castro JC, Kyrpides NC, Cole JR, Tiedje JM, Konstantinidis KT. How much do rRNA gene surveys underestimate extant bacterial diversity? Appl Environ Microbiol. 2018;84:e00014-8.

26. Callahan BJ, McMurdie PJ, Holmes SP. Exact sequence variants should replace operational taxonomic units in marker-gene data analysis. ISME J. 2017;11:ismej2017119.

27. Callahan BJ, McMurdie PJ, Rosen MJ, Han AW, Johnson AJA, Holmes SP. DADA2: High-resolution sample inference from Illumina amplicon data. Nat Methods. 2016:13:nmeth.3869.

28. Figueras MJ, Beaz-Hidalgo R, Hossain MJ, Liles MR. Taxonomic affiliation of new genomes should be verified using average nucleotide identity and multilocus phylogenetic analysis. Genome Announc. 2014;2:e00927-14.

29. MacArthur RH. Population ecology of some warblers of northeastern coniferous forests. Ecology. 1958;39:599-619.

30. Inouye DW. Resource partitioning in bumblebees: experimental studies of foraging behavior. Ecology. 1978;59:672-8.

31. Swanson BO, Gibb AC, Marks JC, Hendrickson DA. Trophic polymorphism and behavioral differences decrease intraspecific competition in a cichlid, Herichthys minckleyi. Ecology. 2003:84:1441-6.

32. Castelle C, Guiral M, Malarte G, Ledgham F, Leroy G, Brugna M, et al. A new iron-oxidizing $/ \mathrm{O}_{2}$-reducing supercomplex spanning both inner and outer membranes, isolated from the extreme acidophile Acidithiobacillus ferrooxidans. J Biol Chem. 2008:283:25803-11.

33. Jeans C, Singer SW, Chan CS, VerBerkmoes NC, Shah M, Hettich RL, et al. Cytochrome 572 is a conspicuous membrane protein with iron oxidation activity purified directly from a natural acidophilic microbial community. ISME J. 2008;2:542

34. Cotter PA, Chepuri V, Gennis RB, Gunsalus RP. Cytochrome o (cyoABCDE) and $d(c y d A B)$ oxidase gene expression in Escherichia coli is regulated by oxygen, pH, and the fnr gene product. J Bacteriol. 1990;172:6333-8.

35. Chan C, McAllister SM, Garber A, Hallahan BJ, Rozovsky S. Fe oxidation by a fused cytochrome-porin common to diverse Fe-oxidizing bacteria. Biorxiv. 2018:228056.
36. Gallon JR. The oxygen sensitivity of nitrogenase: a problem for biochemists and micro-organisms. Trends Biochem Sci. 1981;6:19-23.

37. Rebbapragada A, Johnson MS, Harding GP, Zuccarelli AJ, Fletcher HM, Zhulin IB, et al. The Aer protein and the serine chemoreceptor Tsr independently sense intracellular energy levels and transduce oxygen, redox, and energy signals for Escherichia coli behavior. Proc National Acad Sci. 1997;94:10541-6.

38. Bibikov SI, Biran R, Rudd KE, Parkinson JS. A signal transducer for aerotaxis in Escherichia coli. J Bacteriol. 1997;179:4075-9.

39. Schuler CG, Havig JR, Hamilton TL. Hot spring microbial community composition, morphology, and carbon fixation: implications for interpreting the ancient rock record. Front Earth Sci. 2017;5:97.

40. Hamilton TL, Bennett AC, Murugapiran SK, Havig JR. Anoxygenic phototrophs span geochemical gradients and diverse morphologies in terrestrial geothermal springs. Msystems. 2019;4:e00498-19.

41. Havig JR, Hamilton TL. Productivity and community composition of low biomass/high silica precipitation hot springs: a possible window to earth's early biosphere? Life Basel Switz. 2019;9:64.

42. Caporaso JG, Lauber CL, Walters WA, Berg-Lyons D, Lozupone CA, Turnbaugh PJ, et al. Global patterns of $16 \mathrm{~S}$ rRNA diversity at a depth of millions of sequences per sample. Proc National Acad Sci. 2011; 108(Supplement 1):4516-22.

43. Gohl DM, Vangay P, Garbe J, MacLean A, Hauge A, Becker A, et al. Systematic improvement of amplicon marker gene methods for increased accuracy in microbiome studies. Nat Biotechnol. 2016;34:nbt.3601.

44. Bolger AM, Lohse M, Usadel B. Trimmomatic: a flexible trimmer for Illumina sequence data. Bioinformatics. 2014;30:2114-20.

45. Quast C, Pruesse E, Yilmaz P, Gerken J, Schweer T, Yarza P, et al. The SILVA ribosomal RNA gene database project: improved data processing and webbased tools. Nucleic Acids Res. 2013;41:D590-6.

46. Camacho C, Coulouris G, Avagyan V, Ma N, Papadopoulos J, Bealer K, et al. BLAST+: architecture and applications. BMC Bioinformatics. 2009;10:421.

47. Miller MA, Pfeiffer W, Schwartz T. Creating the CIPRES Science Gateway for Inference of Large Phylogenetic Trees. In: 2010 Gatew Comput Environ Work GCE; 2010. p. 1-8.

48. Stamatakis A. RAxML-VI-HPC: maximum likelihood-based phylogenetic analyses with thousands of taxa and mixed models. Bioinformatics. 2006;22:2688-90.

49. Katoh K, Standley DM. MAFFT Multiple Sequence Alignment Software Version 7: Improvements in Performance and Usability. Mol Biol Evol. 2013;30(4):772-80.

50. Letunic I, Bork P. Interactive tree of life (iTOL) v3: an online tool for the display and annotation of phylogenetic and other trees. Nucleic Acids Res. 2016:44(W1):W242-5.

51. Eren M. A tutorial on assembly-based metagenomics..

52. Li D, Liu C-M, Luo R, Sadakane K, Lam T-W. MEGAHIT: an ultra-fast singlenode solution for large and complex metagenomics assembly via succinct de Bruijn graph. Bioinformatics. 2015;31:1674-6.

53. Langmead B, Salzberg SL. Fast gapped-read alignment with bowtie 2. Nat Methods. 2012;9:357.

54. Eren AM, Esen ÖC, Quince C, Vineis JH, Morrison HG, Sogin ML, et al. Anvi'o: an advanced analysis and visualization platform for 'omics data. Peerj. 2015;3:e1319.

55. Kang DD, Froula J, Egan R, Wang Z. MetaBAT, an efficient tool for accurately reconstructing single genomes from complex microbial communities. Peerj. 2015;3:e1165

56. Parks DH, Imelfort M, Skennerton CT, Hugenholtz P, Tyson GW. CheckM: assessing the quality of microbial genomes recovered from isolates, single cells, and metagenomes. Genome Res. 2015;25:1043-55.

57. Hyatt D, Chen G-L, LoCascio PF, Land ML, Larimer FW, Hauser LJ. Prodigal: prokaryotic gene recognition and translation initiation site identification. BMC Bioinformatics. 2010;11:119.

58. Kanehisa M, Sato Y, Morishima K. BlastKOALA and GhostKOALA: KEGG tools for functional characterization of genome and metagenome sequences. J Mol Biol. 2016:428:726-31.

59. Arkin AP, Cottingham RW, Henry CS, Harris NL, Stevens RL, Maslov S, et al. KBase: the United States Department of Energy Systems Biology Knowledgebase. Nat Biotechnol. 2018;36:566.

60. S.S. Minot, N. Krumm, N.B. Greenfield One codex: a sensitive and accurate data platform for genomic microbial identification bioRxiv. 2015. https://doi. org/10.1101/027607.

\section{Publisher's Note}

Springer Nature remains neutral with regard to jurisdictional claims in published maps and institutional affiliations. 